\title{
PELATIHAN MOTIVASI, MENTAL BERWIRAUSAHA DAN KETERAMPILAN PEMASARAN WIRAUSAHA BARU BINAAN KADIN KOTA BANDUNG
}

\author{
Rr Rachmawati \\ watieroro@yahoo.com \\ Yayan Firmansyah \\ yayan.firmansyah@polban.ac.id
SEKOLAH TINGGI ILMU EKONOMI EKUITAS POLITEKNIK NEGERI BANDUNG

\begin{abstract}
ABSTRAK
Bandung merupakan kota di Indonesia yang menjadi rujukan pasa sektor ekonomi kreatif, ini disebabkan oleh potensi yang besar yang ada di kota ini, untuk menstimulasi potensi yang ada sekaligus dapat meningkatkan taraf hidup masyarakatnya. KADIN Kota Bandung memegang peranan dalam menumbuhkan wirausaha baru ini berdasarkan amanah Pergub No 108 tahun 2015 tentang pengembangan dunia usaha. Tantangan yang dihadapi adalah menurunnya motivasi dan mental pelaku usaha jika dihadapkan persoalan usaha, sebanyak 100 wirausahawan yang terdaftar sebagai wirausahwan baru, saat ini hanya 50\% wirausahawan yang aktif menjalankan usahanya, maka dari itu perlunya meningkatkan motivasi dan mental kewirausahaan melalui pelatihan. Permasalahan lain adalah kurang cakapnya wirausahawan dalam hal pemasaran era industry 4.0 terutama packaging. Dengan dasar kebutuhan tersebut pelatihan motivasi, mental dan keterampilan pemasaran diselenggarakan pelatihan ini dibuat mudah dipahami para pelaku usaha agar usahanya memiliki daya saing. Hasil pelatihan peserta sangat aktif diskusi terlihat dari banyaknya pertanyaan, dan setelah pelatihan peserta merasa mendapatkan motivasi dan mental berwirausaha yang meningkat selain itu omset usaha mengalami peningkatan rata-rata dari keempat jenis usaha sebesar $25 \%$.
\end{abstract}

Kata kunci: Mental, Motivasi, Wirausaha.

\section{PENDAHULUAN}

\subsection{Analisis Situasi}

Pada saat ini menghadapi era generasi 4.0 menurut (WEF, 2016) ada beberapa kerjaan yang hilang seperti pekerjaan yang berkaitan dengan admistrasi perkantoran, akan berkurang 4 jutaan lapangan pekerjaan, manufakur dan produksi akan berkurang 1,6 jutaan lapangan pekerjaan, alasannya karena akan digantikan oleh bergam teknologi yang menyebabkan pekerjaan-pekerjaan tersebut akan berkurang, selain itu menurut Word Economic Forum tahun 2016 akan bertambah seperti business and financial operations diprediksi akan bertambah 492 ribu lapangan kerja, lalu yang bergerak disektor bisnis/ manajemen juga diprediksi akan bertambah sekitar 416 ribu lapangan 
pekerjan. Seperti terlihat pada Gambar 1.1 berikut ini :

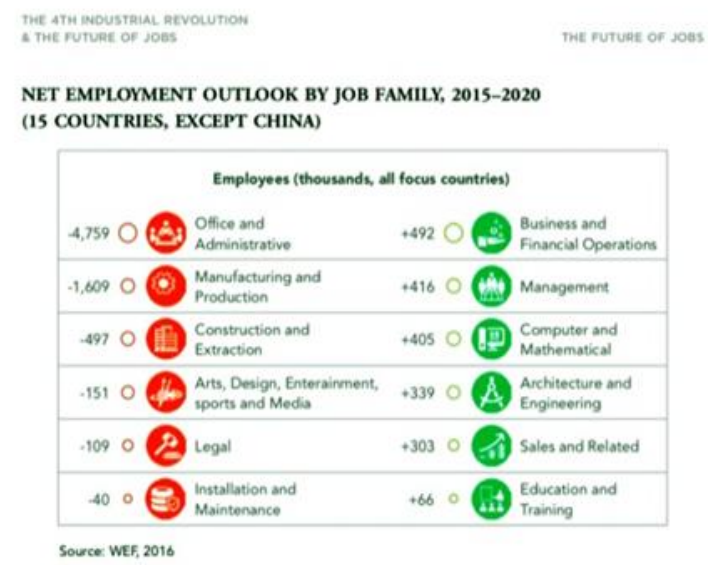

Gambar 1. World Economic Forum 2016.

Dapat dilihat pada Gambar 1 yang berwarna merah adalah pekerjaan yang akan berkurang sedangkan yang berwarna hijau pekerjaan yang diprediksi akan bertambah, perubahan ini juga menurut (Salgues, 2018) akan mendorong society 5.0 atau super smart society maksudnya disini dengan segala keterbukaan informasi akan sangat mudah diakses masyarakat dunia akan banyak pengetahuan dalam melakukan segala hal.

Pada saat ini situasi bisnis yang memiliki perubahan yang di luar prediksi sehingga harus adaptif, lalu adanya globalisasi yang banyak pakar menyebutkan dengan istilah small village membuat persaingan lebih ketat dan hypercompetitive. Dengan pertimbangan di atas memiliki jiwa wirausaha saat ini sudah menjadi keharusan, semakin maju sebuat negara rasio penduduk dengan jiwa wirausahanya Pemerintah menargetkan untuk bisa mencetak satu juta wirausaha baru dalam 5 tahun ke depan. Jumlah wirausaha Indonesia dikala ini baru mencapai 1, 56\% jumlah penduduk, sementara itu bagi standard Bank Dunia jumlah sempurna wirausaha merupakan sebesar 4\% dari jumlah penduduk negeri tersebut Dengan demikian, bagi Presiden Jokowi, Indonesia masih memerlukan, 8 juta wirausaha baru agar dapat mencapai target (Budi, 2018).
Kota Bandung mendukung percepatan dengan membuat program Wirausahawan Baru program tersebut yang tertuang dalam RPJMD 2013-2018 dan masih dilanjutkan sampai saat ini dalam menciptakan 100.000 wirausaha baru yang bertujuan untuk mendukung kesejahteraan masyarakat dan menciptakan lapangan kerja. Setiap tahunnya Dinas KUMKM Kota Bandung menargetkan 1000 orang yang memiliki potensi untuk diberikan pelatihan, dimana pelaksanaannya terdapat di 25 wilayah di Kota Bandung. Selain Dinas KUMKM Kota Bandung, KADIN Kota Bandung juga berperan aktif dalam membina wirausha baru tersebut dengan membina 100 Wirausaha Baru (WUB).

Pada awal mulanya kota Bandung sekitarnya secara tradisional ialah kawasan pertanian, tetapi bersamaan dengan laju urbanisasi menjadikan lahan pertanian jadi kawasan perumahan dan setelah itu tumbuh jadi kawasan industri serta bisnis, cocok dengan transformasi ekonomi kota biasanya. Zona perdagangan serta jasa dikala ini memainkan peranan berarti hendak perkembangan ekonomi kota ini disamping terus berkembangnya zona industri. Bersumber pada Survei Sosial Ekonomi Wilayah (Suseda) pada tahun 2006, 35,92\% dari total angkatan kerja penduduk kota ini terserap pada zona perdagangan, $28.16 \%$ pada zona jasa serta $15,92 \%$ pada zona industri. Sebaliknya zona pertanian cuma meresap $0,82 \%$, sedangkan sisa $19,18 \%$ pada zona angkutan, bangunan, keuangan serta lainnnya. (https://id.wikipedia.org/wiki/Kota_Bandun g diakses 11 Januari 2019).

\subsection{Identifikasi Masalah}

KADIN merupakan organisasi resmi bekumpulkanya pengusaha di Indonesia memiliki peran aktif dalam membina WUB berjumlah 100 WUB, dimaa terdapat 4 sektor jenis usaha seperti jasa, produk makanan dan minuman, handy craft dan multimedia. Dari survey awal tim STIE Ekuitas dan Polban bertemu dengan perwakilan WUB Binaan KADIN 
mendapatkanan temuan pertama dari 100 WUB yang dibina yang aktif hanya 70 WUB saja atau dengan kata lain $70 \%$ saja ini menjadi permasalahan sendiri terkait dengan motivasi dan mental berwirausaha, pada tahun 2020 hasil empiris mendapatkan temuan bahwa motivasi memiliki pengaruh prositif terhadap produktivitas (Tjahjawati \& Firmansyah, 2020) Tantangan wirausaha baru kurangnya konsistensi, lalu omset yang tidak mencapai target berdasarkan survey tim STIE Ekuitas dan Polban mendapatkan temuan bahwa metode pemasaran khususnya packaging kurang menarik bagi minat pelanggan ini perlu diperbaiki (Firmansyah et al., 2019).

\section{METODOLOGI PELAKSANAAN}

Bersumber pada kasus yang dialami oleh mitra semacam tertulis dalam bab sebelumnya, sebagian alternatif pemecahan yang bisa ditawarkan yakni membagikan motivasi dan mental serta keterampilan dalam berwirausaha

pelaksanaan kegiatan ini dibagi ke dalam empat tahap, yaitu metode pendekatan masalah, prosedur kerja dan rencana kegiatan. Tahapan tersebut yaitu ;

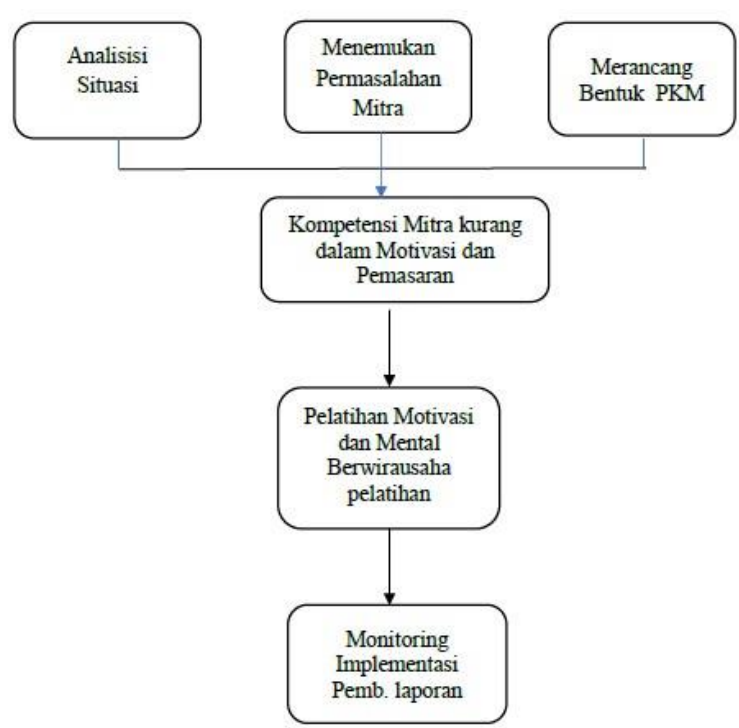

Gambar 2. Tahapan Pelaksanaan.

1. Melakukan kunjungan dan menganalisis dan permasalahan yang terdapat di WUB binaan KADIN Kota Bandung. Pada tahap ini diakhiri dengan merancang bentuk PKM

2. Menemukan mantra kekurangan kompetensi dalam motivasi dan mental beriwirausaha

3. Melaksanakan pelatihan motivasi dan mental berwirausaha dan pelatihan pemasaran terutama pembuatan packaging yang menarik. Pelatihan motivasi dan mental berwirausaha selain metode telling/ceramah, tanya jawab juga dengan metode coaching. Disertai dengan contoh-contoh wirausahaawan sukses dibidangnya lalu yang dapat menjadi inspirasi pelaku usaha dan simulasi permainan.

4. Melakukan monitoring, implementasi selama 1 bulan setelah kegiatan pelatihan. Diakhiri dengan pembuatan laporan.

\section{HASIL DAN LUARAN}

\subsection{Hasil}

Secara umum kegiatan PKM ini dapat berjalan sesuai dengan rencana, berikut adalah hasil secara rinci 1 . Jumlah peserta dapat dilihat pada tabel 3.1 sebagai berikut :

Tabel. 3.1 Jumlah dan Jenis Usaha Peserta

\begin{tabular}{|c|c|c|c|}
\hline No & $\begin{array}{l}\text { Jenis } \\
\text { Usaha }\end{array}$ & Jumlah & $\begin{array}{c}\text { Persentase } \\
(\%)\end{array}$ \\
\hline 1 & Kuliner & 52 & $75 \%$ \\
\hline 2 & Multimedia & 12 & $17 \%$ \\
\hline 3 & Handicraft & 2 & $3 \%$ \\
\hline 4 & Fashion & 3 & $4 \%$ \\
\hline & Total & 69 & $100 \%$ \\
\hline
\end{tabular}

Pada Tabel 3.1 jumlah UMKM yang hadir berjumlah 69 UMKM, persentase terbesar adalah jenis usaha kuliner sebesar $75 \%$ atau 52 UMKM, lalu jenis usaha multimedia sebesar $17 \%$ atau 12 UMKM sisanya jenis usahanya Handicraft dan fashion. Tabel selanjutnya hasil dari pelatihan ini dengan menyebarkan 
kuesioner sebagai feedback dari kegiatan Pengabdian Kepada Masyarakat sebagai berikut:

Tabel. 3.2 Omset Setelah Pelatihan

$\begin{array}{rlrc}\text { No } & \begin{array}{l}\text { Jenis } \\ \text { Usaha }\end{array} & \begin{array}{l}\text { Persenta } \\ \text { se }(\%)\end{array} & \text { Ket } \\ 1 & \text { Kuliner } & 27 \% & \text { Meningkat } \\ 2 & \text { Multimedia } & 20 \% & \text { Meningkat } \\ 3 & \text { Handicraft } & 30 \% & \text { Meningkat } \\ 4 & \text { Fashion } & 23 \% & \text { Meningkat } \\ & \text { Rata-rata } & 25 \% & \\ & & & \end{array}$

Dapat dilihat dari tabel 3.2 dari kempat jenis usaha rata-rata yang paling tinggi menigkatnya adalah Handicraft sebesar $30 \%$. Pada peringkat kedua jenis usaha kuliner sebesar 27\%, ketiga Fashion 23\% dan terakhir adalah multimedia sebesar $20 \%$. Rata-rata keseluruhanya adalah $25 \%$ ini menandakan kegiatan PKM ini memiliki manfaat praktis. Berikut beberapa foto kegiatan pelatiahn dalam PKM ini sebgai berikut:

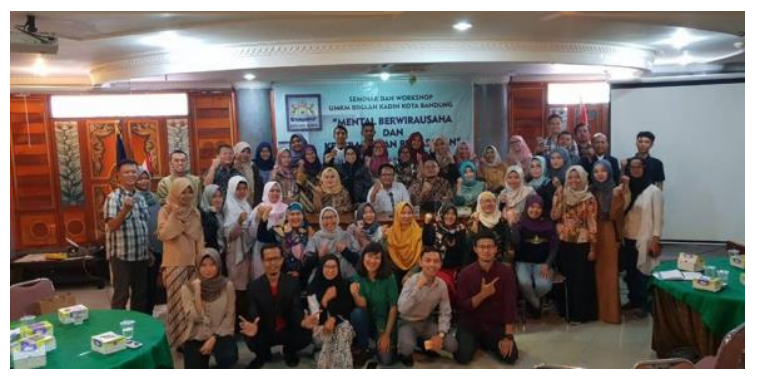

Gambar 3. Suasana Jalanya Pelatihan.

Susana kegiatan PKM ini cukup meriah, sesi foto antara narasumber dan peserta kegiatan. Berikut foto pemberian piagam penghargaan oleh Kadin Kota Bandung kepada Narasumber

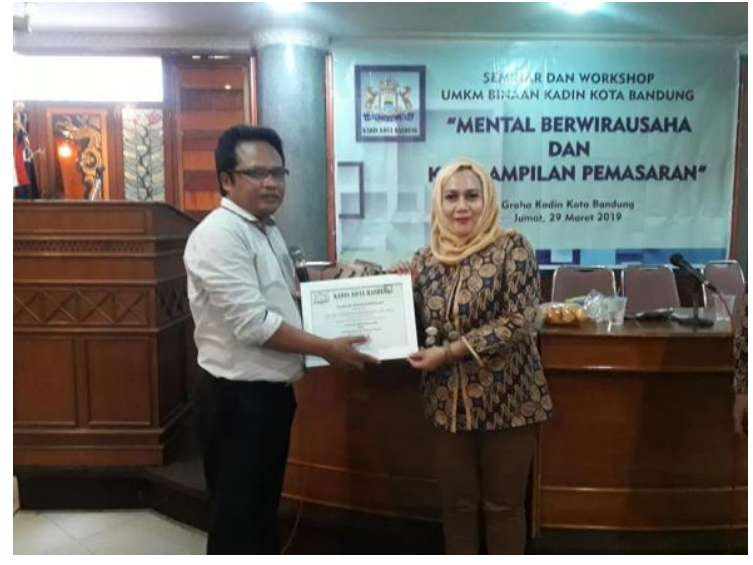

Gambar 4. Penyerahan Piagam

Penghargaan .Kepada Narasumber

Dr Rr. Rachmawati,S.E.,M.Si.

Pada gambar 4 Pengurus Kadin Kota Bandung bidang UMKM Drs Bambang Tris Bintoro menyerahkan piagam penghargaan kepada Dr Rr. Rachmawati,S.E.,M.Si, selanjutnya pemberian penghargaan kepada narasmuber ke II seperti foto dibawah ini :

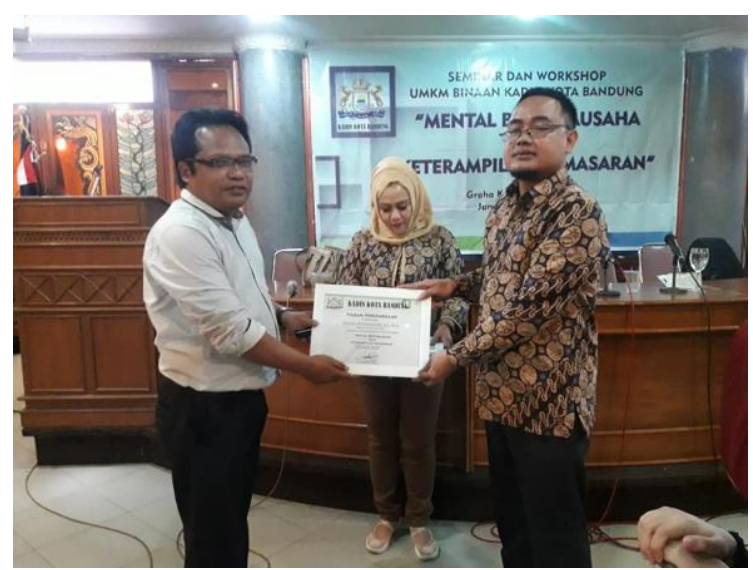

Gambar 5. Penyerahan Piagam

Penghargaan .Kepada Narasumber

Yayan Firmansyah,S.E.,M.Si.

Pada gambar 5 diberikan piagam penghargaan kepada Narasumber Yayan Firmansyah,S.E., M.Si.

\subsection{Luaran}

Jenis luaran yang akan dihasilkan dari kegiatan pengabdian masyarakat adalah;

1. Jasa, memiliki keterampilan dalam pemasaran terutama packaging yang lebih menarik pada UKM 
Leker Donut's dan UKM Gayemeun Bandung. Meningkatkan

2. Meningkatkan keterampilan keterampilan baru menggunakan online marketing pada UKM Good Vobe Warll Art dalm memperluas jangkauan pasar

3. Meningkatkan pengetahuan tentang penggelolaan karyawan murai perekrutan, pelatihan dan pengembangan karyawan, mempertahankan karyawan, dan pemutusan hubungan kerja.

4. Produk berupa; Materi pelatihan Mental Berwirausaha dan Teknik Pemasaran sebagai berikut:

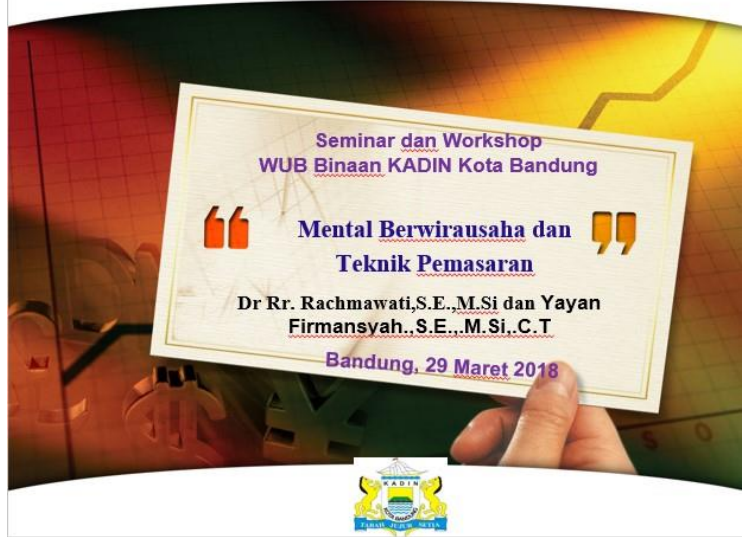

Gambar 6. Cover Materi pelatihan Mental Berwirausaha dan Teknik Pemasaran.

\section{KESIMPULAN DAN SARAN}

Hasil pelatihan peserta sangat aktif diskusi terlihat dari banyaknya pertanyaan, dan setelah pelatihan peserta merasa mendapatkan motivasi dan mental berwirausaha yang meningkat selain itu rata-rata omset usaha mengalami peningkatan sebesar 25\%. Pelatihan semacam ini baiknya dilakukan secara konsisten dengan pendampingan dan menggunakan media baik offline dan online. Dapat dilanjutkan dengan pelatiahan digitalisasi UMKM dan pembuatan aporan keuangan agar bankable.

\section{UCAPAN TERIMAKASIH}

Terimakasih kepada pimpinan STIE Ekuitas, Kadin Kota Bandung dan Politeknik Negeri Bandung yang telah memberikan fasilitas atas terselenggaranya Pengabdian Kepada Masyarakat ini.

\section{DAFTAR PUSTAKA}

Budi, F. F. (2018). Pengaruh Pendidikan Kewirausahaan Dalam Menumbuhkan Minat Berwirausaha. Jurnal Pengabdian Dan Kewirausahaan, 2(1), 7. http://finance.detik.com/beritaekonomi-bisnis/d-

Firmansyah, Y., Basuki, T. I., \& Bachmid, F. S. (2019). PROGRAM PENDAMPINGAN UKM LAUDIA KACANG KOTA. 1(1), 48-54.

Salgues, B. (2018). Society 5.0. Society 5.0. https://doi.org/10.1002/97811195073 14

Tjahjawati, S. S., \& Firmansyah, Y. (2020). Pengaruh Motivasi Kerja dan Knowledge Management Terhadap Produktivitas Kerja Karyawan Konveksi Sepatu dan Sandal XYZ Bandung. Eko Dan Bisnis: Riau Economic and Business Review, 11(3). https://doi.org/10.36975/jeb.v11i3.28 0

WEF. (2016). World Economic Forum Annual Report 2016. American Journal of Pharmaceutical Education, 80(8), S9.

(https://id.wikipedia.org/wiki/Kota_Bandun g diakses 11 Januari 2019). 